\title{
Multiple Major Thrombo-Embolic Events, including Stroke, in a Patient with Combined Congenital Anti-Thrombin III Deficiency and MTHFR Homozygous Mutation
}

\author{
Islam I. Zaid1, Nora I. Abbas², Ehab Shaker'1, Foad Abd-Allah1 \\ ${ }^{1}$ Departement of Neurology, Faculty of Medicine, Cairo University, Cairo, Egypt \\ ${ }^{2}$ Departement of Critical Care Medicine, Faculty of Medicine, Cairo University, Cairo, Egypt \\ Email: foad.abdallah@kasralainy.edu.eg
}

How to cite this paper: Zaid, I.I., Abbas, N.I., Shaker, E. and Abd-Allah, F. (2017) Multiple Major Thrombo-Embolic Events, including Stroke, in a Patient with Combined Congenital Anti-Thrombin III Deficiency and MTHFR Homozygous Mutation. World Journal of Cardiovascular Diseases, 7, 71-78.

https://doi.org/10.4236/wjcd.2017.73008

Received: January 29, 2017

Accepted: March 24, 2017

Published: March 27, 2017

Copyright ( 92017 by authors and Scientific Research Publishing Inc. This work is licensed under the Creative Commons Attribution International License (CC BY 4.0).

http://creativecommons.org/licenses/by/4.0/ (c) (i) Open Access

\begin{abstract}
We report a case of a young male patient suffering from congenital AntiThrombin III (AT III) deficiency, presented with four major thrombotic events. These events were acute coronary syndrome (Non-ST elevation myocardial infarction), cerebral infarction, peripheral acute upper limb (UL) ischemia and bilateral extensive deep venous thrombosis. The latter two developed despite that the patient was receiving full anticoagulation therapy. His International normalized ratio (INR) was 2.5. Eventually, the patient developed pulmonary embolism and died. He had a prominent family history of thrombotic events. Screening for AT III deficiency in young patients with thrombotic event (thrombophilia) is essential especially those having family history of the latter. This is justified as thrombotic events may occur in up to $80 \%$ of these patients. Our patient with 4 major thrombotic events ending in fatality in less than 1 month deserves the nomenclature.
\end{abstract}

\section{Keywords}

Thrombophilia, Thrombosis, Congenital AT III Deficiency, Stroke, Acute Coronary Syndrome, Deep Venous Thrombosis, Acute Limb Ischemia

\section{Background}

Since Virchow had described his triad in 1856, the three major factors responsible for venous thrombosis are endothelial injury, venous stasis and a hypercoagulable condition [1]. Attempts at early identification and treatment of venous thrombotic event (VTE) are aiming to better life quality as well as survival out- 
come. Thrombotic events may occur in $30 \%$ to $80 \%$ in AT III deficiency patients [2].

\section{Case Presentation}

A 26 years old, apparently healthy male presented to our emergency with acute onset of left sided weakness associated with transient episode of loss of consciousness. No history of headache, vomiting, fever, convulsions or head trauma prior to onset. Initial computed tomography (CT) brain imaging revealed no apparent abnormalities.

One day after admission, he started to complain of a severe agonizing pain in the right upper limb which was not investigated. Two days following admission, a follow-up CT of the brain revealed a right fronto-tempero-parietal cerebral infarction (Figure 1). Subsequent Magnetic resonance imaging (MRI) confirmed the diagnosis \& Magnetic resonance angiography (MRA) was done and revealed right Middle cerebral artery (MCA) occlusion.

He was clinically reassessed: History taking revealed that he was chronic heavy smoker (Smoking index 1200) 60 cigarettes/day for 20 years, Right handed, on multiple substance abuse: Tramadol, cannabis, alcohol. There was no History of hypertension, diabetes mellitus or rheumatic heart diseases.

The patient was still persistently complaining of severe progressive agonizing right Upper limb pain.

His family history was positive for thromboembolic events from his paternal side. His elder brother died of acute cerebrovascular stroke (CVS) at the age of

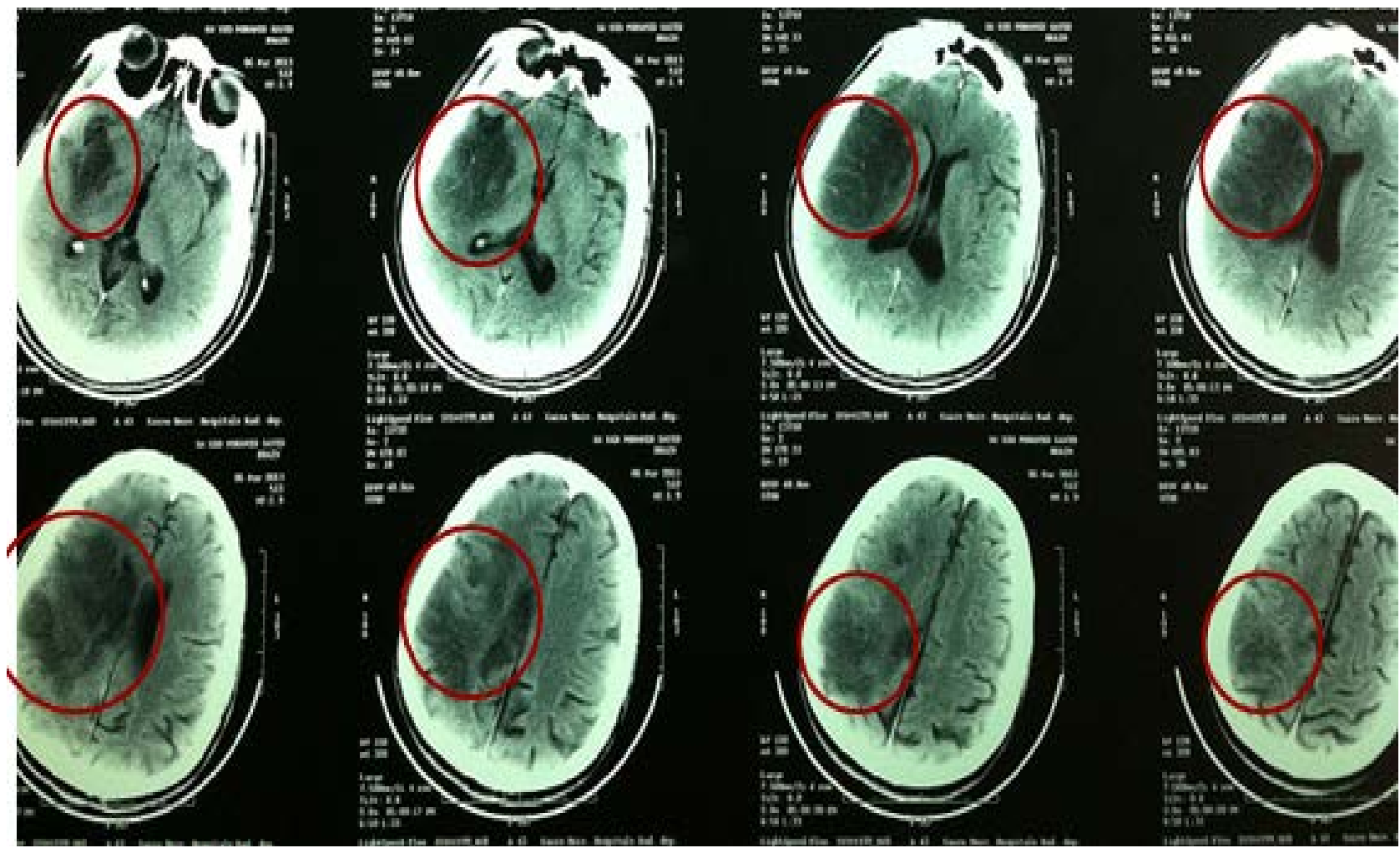

Figure 1. CT Brain: Right middle cerebral artery ischemic infarct. 
22 yrs. His elder sister died of post-partum pulmonary embolism (PE) at the age of 20 yrs. His younger sister suffered from post-partum sagittal sinus thrombosis at the age of 18 yrs. His father used to suffer of recurrent DVTs \& one episode of mesenteric vascular occlusion (MVO). One of his aunts died of post-partum PE $\&$ the other one experienced 2 episodes of post-partum DVT.

Examination showed an average built patient with low grade fever; temperature $\left(37.5^{\circ} \mathrm{C}\right)$ and respiratory rate was 25 breaths/min and left radial pulse was regular with a rate of 92 . The Right UL pulsations were absent (radial, ulnar, brachial, axillary and Subclavian arteries). Other peripheral pulsations were adequately felt. Blood pressure measured from Left side was 120/80 mmHg.

The patient had left sided hemiparesis grade 0 both in upper \& lower limb. There were facial asymmetry on the left side, Lt sided hyposthesia and slurred speech despite good formulation. The patient had severe Right UL tenderness, coldness and pallor.

Laboratory work was normal, except for mildly elevated ESR 25, The Creatinine kinase level was 2935 U/L (Normal 55 - 170 units/L). Creatinine kinase MB fraction was $41.5 \mathrm{ng} / \mathrm{ml}$ (Normal 0 - $3 \mathrm{ng} / \mathrm{ml}$ ). Cardiac Troponin level was 0.16 $\mathrm{ng} / \mathrm{ml}$.

ECG showed Sinus rhythm with frequent premature beats, intraventricular conduction delay, Left anterior fascicular block and T-wave inversion in Leads I and aVL. Chest X-Ray showed Cardiomegaly and increased bronchovascular markings. Echocardiography showed akinetic apex (anterior wall, anterior septum), left apical thrombus and EF 35\% with normal appearance of left atrium (Figure 2). Right UL duplex revealed thrombosis of arterial system from origin of the brachial artery till the end of radial artery, Patent ulnar artery with no blood flow and extensive DVT. At this point the patient was felt to have a major coagulopathy with events affecting brain heart and upper limb that compelled us to start full anticoagulation with LMWH.

Advanced thrombophilia testing revealed Anti-thrombin III to be deficient. It's percentage was 53 (NL: 83\% - 111.0\%). Methyl-tetrahydrofolatereductase (MTHFR) gene showed mutation of homozygous type. The serum homocystiene was higher than normal 16.40 (NL: $5.08-15.39 \mu \mathrm{ml} / \mathrm{L}$ ). The anti-nuclear antibodies, Anticardiolipin, Protein C, Protein S, Factor V Leiden \&Prothrombin (PTN) genes did not show any abnormalities. Lupus Anticoagulant was positive with a mean patient control ratio of 129.8 (normal range: 34.0 - 40.0).

On the 12th day of admission, Fogarty's Catheter thrombectomy was done twice for the right UL ischemia. The following day, another two trials were done. Despite being on therapeutic LMWH, all these trials of thrombectomy failed and above elbow amputation was undertaken after appearance of line of demarcation about 1 week later.

Full anticoagulant therapy was continued with LMWH overlapping oral anticoagulants, dual antiplatelets and vitamins (Vitamin B complex \& large dose folic acid). Patient started to regain power with improvement regarding dysarthria \& facial weakness. Amputation stump was healing. Follow up Trans-cranial Doppler (TCD) and CT angiography showed that MCA starts to recanalize. 




Figure 2. Echo-Heart: Left apical thrombus.

While on oral warfarin therapy, and despite that INR was in the therapeutic level, the patient started complaining of pain in the left LL. Venous duplex revealed bilateral acute extensive DVT in common iliac veins. In addition, sub-acute thrombi were detected at the level of common iliac vein, external iliac vein, common femoral vein and superficial femoral vein, on top of chronic thrombosis detected at the level of the popliteal vein.

\section{Outcome}

The patient died two weeks later suddenly with futile CPR although therapeutic INR was reached. Our patient with 4 major thrombotic events most probably died from extensive pulmonary embolism.

\section{Discussion}

Anti-thrombin is a natural inhibitor of thrombin as well as of Factors Xa, IXa, XIIa and kallikrien [3]. Congenital anti-thrombin deficiency is a rare autosomal dominant hereditary disorder [4]. The incidence of congenital AT III deficiency ranged from 1/2000 to $1 / 20,000$. [2] [5] [6]. Egeberg was the first to report that quantitative deficiency of anti-thrombin III (AT-III) is associated with increased risk of thrombosis [7].

Congenital AT-III abnormality is classified into two types; Type I that hasa reduced level of functional AT (due to decreased synthesis or increased turnover or both) and type II that is functionally defective. The latter type has underlying 3 subtypes depending on which part of the molecule is functionally defective [8] [9]. Our patient had type I abnormality.

The gene for Anti-thrombin III is located on Chromosome 1q. Familial AT-III deficiency probably confers a higher risk of thrombosis than Protein $\mathrm{C}$ or Protein S deficiencies [10]. The chance of finding AT III deficiency is increased if there is a history of familial or recurrent venous thrombosis [11]. In addition, many symptomatic patients simultaneously carry more than one genetic risk 
factor. In our case, both the patient and his sister had AT III deficiency and MTHFR mutation supporting that thrombophilia represents a polygenic rather than a monogenic clinical phenotype [12].

Homozygous anti-thrombin deficiency is incompatible with life. In heterozygous AT III deficiency, about $50 \%$ of asymptomatic family members develop the first thrombotic event before age of 25 years [13]. Thrombosis is uncommon in infancy and childhood, but the incidence rises sharply between 15 and 30 years of age [2] [14]. A 50\% probability for the first thromboembolic event was reached at the age of 21 years in AT III deficiency patients. The most common site of the first thrombotic event was pulmonary embolism with or without deep vein thrombosis. [14].

Most patients with arterial stroke have predisposing risk factors as diabetes, hypertension, hyperlipidemia, smoking or valvular heart disease. When such risk factors are absent, one should suspect hypercoagulable disorders [21]. While hyperhomocystenemia carry a moderate risk for arterial stroke [22]. However a higher prevalence of AT III deficiencies in ischemic stroke up to $23 \%$ has also been reported [23].

The major clinical manifestations of AT III deficiency are young age at onset, idiopathic thrombosis, family history, and recurrent venous thrombo-embolism [15]. Although, previous studies have suggested that hyper-coagulation is the major cause of only a minority ( $1 \%$ to $4 \%$ ) of all ischemic strokes [16] [17], it may be relevant in the pathogenesis of strokes in young patients [18] [19] [20]. Nevertheless, arterial thrombosis is not typical of AT deficiency it does occur and in our patient harboring a second thrombophilic defect with MTHFR gene mutation might have affected the presenting phenotype.

The most common form of genetic hyperhomocysteinemia results from mutation of MTHFR gene with reduced enzymatic activity [24]. Hyperhomocysteinemia-even if mild—is an independent risk factor for VTE [25] [26]. Inherited hyperhomocysteinemia can be further exaggerated by deficiencies in vitamins B6, B12, and folic acid [27]. Hyperhomocysteinemia is typically managed with vitamin B6, folic acid, and vitamin B12 supplementation and trimethylglycine (TMG) or betaine [28]. Taurine supplementation also has been found to reduce homocysteine levels [29].

From a clinical standpoint, our patient's clinical presentation could have been explained as a cardioembolicmanifestations of myocardial infarct in a patient with substance abuse if it were not for the DVT. One could argue that low levels of antithrombin could have resulted from acute thrombosis or heparin therapy. However the strong family history and the extensive DVT complicating the clinical scenario point out to the underlying hereditary coagulopathy.

Although after a search in the literature we did not find the term catastrophic AT deficiency similar to the catastrophic Antiphospholipid syndrome, we did found a case of a catastrophic secondary antiphospholipid syndrome with AT deficiency in a 38 year old woman with SLE [32]. Our patient with 4 major thrombotic events ending in fatality in less than 1 month deserves the nomen- 
clature.

He had developed DVT of lower limbs inspite of warfarin therapy with therapeutic INR. Was the INR falsely prolonged by LA which was positive in our patient or was the patient adequately anticoagulated with warfarin nevertheless developed DVT is a point that could not be settled.

We planned to repeat the Antithrombin level assessment after 3 months since it was done in the acute stage, which could affect the level. In the acute stage, nothing can be offered to solve this problem except to perform the test during the acute event. If normal, it basically excludes the diagnosis, and if low, in the setting of acute thrombosis, it should be repeated later after the acute event, when patient is off heparin to confirm the diagnosis.

Treatment of acute venous thromboembolism consists of unfractionated heparin or LMWH followed by warfarin anticoagulation for 3-6 months. Warfarin can be started within the first 24 hours. Heparin or LMWH is continued for at least five days and until the prothrombin time has been in the therapeutic range (INR of 2.0 to 3.0) for at least 24 hours [30]. According to ACCP(American college of chest physician) guidelines, first episode of VTE and documented AT-III deficiency or homocystinemia, needs either anticoagulation for 6 - 12 months (Grade 1A) or indefinite anticoagulation (Grade 2C) [31].

In certain situations of severe thrombosis inspite of adequate anticoagulation, replacement therapy with AT becomes indicated or argatroban which is a direct thrombin inhibitor bypassing antithrombin. Unfortunately both drugs were not available in Egyptian market at the time of presentation. Not only availability is an issue, but also probably cost would have been a major obstacle for use in governmental hospital in low-middle income country with limited resources.

\section{Learning Points}

- Early adequate screening of thrombophilia when suspected as well as to family members of affected high-risk patients could save lives and minimize morbidity.

- Never neglect even a minor complaint in a thrombophilic patient (particularly combined genetic defects) for early detection of VTE and avoidance of complication.

- Genetic analysis of high-risk families to allow early detection.

\section{References}

[1] Arfvidsson, B., Eklof, B., Kistner, R.L., Masuda, E.M. and Sato, D.T. (2000) Risk Factors for Venous Thromboembolism Following Prolonged Air Travel: Coach Class Thrombosis. Hematologyl Oncology Clinics of North America, 14, 391-400.

[2] Hirsh, .J, Piovella, F. and Pini, M. (1989) Congenital Antithrombin III Deficiency: Incidence and Clinical Features. The American Journal of Medicine, 87, 34-38. https://doi.org/10.1016/0002-9343(89)80529-7

[3] Oelschläger, C., Römisch, J., Staubitz, A., Stauss, H., Leithäuser, B., Tillmanns, H., et al. (2002) Antithrobin III Inhibits $\kappa$ B Activation in Human Monocytes and Vascular Endothelial Cells. Blood, 99, 4015-4020. https://doi.org/10.1182/blood.V99.11.4015 
[4] Lane, D.A., Bayston, T., Olds, R.J., Fitches, A.C., Cooper, D.N., Millar, D.S., et al. (1997) Antithrombin Mutation Database: 2nd (1997) Update. For the Plasma Coagulation Inhibitors Subcommittee of the Scientific and Standardization Committee of the International Society on Thrombosis and Haemostasis. Thrombosis and Haemostasis, 77, 197-211.

[5] Martinelli, I., Mannucci, P.M., De, S.V., Taioli, E., Rossi, V., Crosti, F., et al. (1998) Different Risks of Thrombosis in Four Coagulation Defects Associated with Inherited Thrombophilia: A Study of 150 Families. Blood, 92, 2353-2358.

[6] Rosenberg, R.D. (1975) Actions and Interactions of Antithrombin and Heparin. The New England Journal of Medicine, 292, 146-151. https://doi.org/10.1056/NEJM197501162920307

[7] Sas, G., Blasko, G., Banhegyi, D., Jako, J. and Palos, A. (1974) Abnormal Antithrombin III (Antithrombin III "Budapest") as a Cause of a Familial Thrombophilia. Thrombosis et Diathesis Haemorrhagica, 32, 105-115.

[8] Sas, G. (1984) Hereditary Antithrombin III Deficiency: Biochemical Aspects. Haematologica (Budapest), 17, 81-86.

[9] Mannucci, P.M., Tripodi, A. and Mari, D. (1984) Congenital Deficiency of Anticoagulant Proteins (Antithrombin III and Protein C). Haematologica, 69, 730-749.

[10] Lane, D.A., Mannucci, P.M., Bauer, K.A., Bertina, R.M., Bochkov, N.P., Boulyjenkov, V., et al. (1996) Inherited Thrombophilia: Part 1. Thrombosis and Haemostasis, 76, 651-662.

[11] Briet, E., van der Meer, F.J., Rosendaal, F.R., Houwing-Distermaat, J.J. and van Houwelingen, H.C. (1994) The Family History and Inherited Thrombophilia. British Journal of Haematology, 87, 348-345. https://doi.org/10.1111/j.1365-2141.1994.tb04920.x

[12] Seligsohn, U. and Lubetsky, A. (2001) Genetic Susceptibility to Venous Thrombosis. The New England Journal of Medicine, 344, 1222-1231. https://doi.org/10.1056/NEJM200104193441607

[13] The British Committee for Standards in Haematology (1990) Guidelines on the Investigation and Management of Thrombophilia. Journal of Clinical Pathology, 43, 703-709. https://doi.org/10.1136/jcp.43.9.703

[14] Pabinger, I. and Schneider, B. (1996) Thrombotic Risk in Hereditary Antithrombin III, Protein C, or Protein S Deficiency. A Cooperative, Retrospective Study. Gesellschaft fur Thrombose- und Hamostaseforschung (GTH) Study Group on Natural Inhibitors. Arteriosclerosis, Thrombosis, and Vascular Biology, 16, 742-748. https://doi.org/10.1161/01.ATV.16.6.742

[15] Mateo, J., Oliver, A., Borrell, M., Sala, N. and Fontcuberta, J. (1998) Increased Risk of Venous Thrombosis in Carriers of Natural Anticoagulant Deficiencies. Results of the Family Studies of the Spanish Multicenter Study on Thrombophilia (EMET study). Blood Coagulation \& Fibrinolysis, 9, 71-78.

[16] Takahashi, J., Ito, M., Okude, J., Gohda, T., Wakamatsu, Y., Sasaki, S., et al. (2003) Pulmonary Thromboembolectomy in Congenital Antithrombin III Deficiency Associated with Acute Pulmonary Embolism-Report of a Case. Annals of Thoracic and Cardiovascular Surgery, 9, 192-196.

[17] Ridker, P.M., Hennekens, C.H., Lindpaintner, K., Stampfer, M.J., Eisenberg, P.R. and Miletich, J. (1995) Mutation in the Gene Coding for Coagulation Factor V and the Risk of Myocardial Infarction, Stroke, and Venous Thrombosis in Apparently Healthy Men. The New England Journal of Medicine, 332, 912-917. https://doi.org/10.1056/NEJM199504063321403

[18] Haberl, R.L., Biniasch, O., Ott, M., Peinemann, A., Wick, M. and Kempter, B. 
(1995) Infrequency of Stroke Caused by Specific Coagulation Disorders. Cerebrovascular Diseases, 5, 391-396. https://doi.org/10.1159/000107890

[19] Martinez, H.R., Rangel-Guerra, R.A. and Marfil, L.J. (1993) Ischemic Stroke Due to Deficiency of Coagulation Inhibitors: Report of 10 Young Adults. Stroke, 24, 19-25. https://doi.org/10.1161/01.STR.24.1.19

[20] Barinagarcrementeria, F., Cantu-Brito, C., De La Peria, A. and Izaguirre, R. (1994) Prothrombotic States in Young People with Idiopathic Stroke: A Prospective Study. Stroke, 25, 287-290. https://doi.org/10.1161/01.STR.25.2.287

[21] Munts, A.G., van Genderen, P.J., Dippel, D.W., van Kooten, F. and Koudstaal, P.J. (1998) Coagulation Disorders in Young Adults with Acute Cerebral Ischaemia. Journal of Neurology, 245, 21-25. https://doi.org/10.1007/s004150050169

[22] Soare, A.M. and Popa, C. (2010) Deficiencies of Proteins C, S and Antithrombin and Factor V Leiden and the Risk of Ischemic Strokes. Journal of Medicine and Life, 3, 235-238.

[23] Moster, M. (2003) Coagulopathies and Arterial Stroke. Journal of Neuro-Ophthalmology, 23, 63-71. https://doi.org/10.1097/00041327-200303000-00012

[24] Bushnell, C.D. and Goldstein, L.B. (2000) Diagnostic Testing for Coagulopathies in Patients with Ischemic Stroke. Stroke, 31, 3067-3078.

[25] Kang, S.S., Wong, P.W., Susmano, A., Sora, J., Norusis, M. and Ruggie, N. (1991) Thermolabile Methylenetetrahydrofolate Reductase: An Inherited Risk Factor for Coronary Artery Disease. The American Journal of Human Genetics, 48, 536-545.

[26] D’Angelo, A and Selhub, J. (1997) Homocysteine and Thrombotic Disease. Blood, 90, 1-11.

[27] denHeijer, M., Kostor, T., Blom, H.J., Bos, G.M., Briet, E., Reitsma, P.H., et al. (1996) Hyperhomocysteinemia as a Risk Factor for Deep-Vein Thrombosis. The New England Journal of Medicine, 334, 759-762. https://doi.org/10.1056/NEJM199603213341203

[28] Lockwood, C.J. (2002) Inherited Thrombophilias in Pregnant Patients. Obstetrics \& Gynecology, 99, 333-341. https://doi.org/10.1097/00006250-200202000-00026

[29] Van Guldener, C. and Stehouwer, C.D. (2001) Homocysteine-Lowering Treatment: An Overview. Expert Opinion on Pharmacotherapy, 2, 1449-1460. https://doi.org/10.1517/14656566.2.9.1449

[30] Zulli, A., Lau, E., Wijaya, B.P., Jin, X., Sutarga, K., Schwartz, G.D., Learmont, J., Wookey, P.J., Zinellu, A., Carru, C. and Hare, D.L. (2009) High Dietary Taurine Reduces Apoptosis and Atherosclerosis in the Left Main Coronary Artery: Association with Reduced CCAAT/Enhancer Binding Protein Homologous Protein and Total Plasma Homocysteine but Not Lipidemia. Hypertension, 53, 1017-1022. https://doi.org/10.1161/HYPERTENSIONAHA.109.129924

[31] Geerts, W.H., Pineo, G.F., Heit, J.A., Bergqvist, D., Lassen, M.R., Colwell, C.W. and Ray, J.G. (2004) Prevention of Venous Thromboembolism: The Seventh ACCP Conference on Antithrombotic and Thrombolytic Therapy. Chest, 126, 338S-400S.

[32] Gallus, A.S. (2005) Management Options for Thrombophilias. Seminars in Thrombosis and Hemostasis, 31, 118-126. https://doi.org/10.1055/s-2005-863814 
Submit or recommend next manuscript to SCIRP and we will provide best service for you:

Accepting pre-submission inquiries through Email, Facebook, LinkedIn, Twitter, etc. A wide selection of journals (inclusive of 9 subjects, more than 200 journals)

Providing 24-hour high-quality service

User-friendly online submission system

Fair and swift peer-review system

Efficient typesetting and proofreading procedure

Display of the result of downloads and visits, as well as the number of cited articles Maximum dissemination of your research work

Submit your manuscript at: http://papersubmission.scirp.org/

Or contact wicd@scirp.org 